\title{
Social Problems in Turner Syndrome
}

\author{
Keinosuke Fujita \\ Department of Pediatrics, Osaka City General Hospital, Osaka, Japan
}

\begin{abstract}
Turner girls, women and their families have several social problems at all stages of life. The family usually feel shock at the diagnosis of Turner syndrome. In 1991, we organized a Turner society in Osaka. Several other Turner societies have been established in different areas in Japan. A questionnaire about social problems was sent to the members of the Turner Society. Ninety-four responded, and the response rate was $56 \%$. Half of the parents feel that during infancy the Turner girls were difficult to bring up. One third of the mothers indicated that they were too nervous to bring up the baby. During school life, half of the Turner girls were bullied. In academic performance, two thirds of Turner girls were average or better than average. Many Turner girls said that they disliked mathematics and gymnastics. Information about Turner syndrome is important for Turner girls. Not a few of them were upset when they got the information. Of 10 individuals who had a job, three Turner women had experienced difficulty in finding a job. One third of Turner women above 19 years of age have boy friends. We need to follow them up as to marriage.
\end{abstract}

Key words: Turner syndrome, social problem, Turner society

\section{Introduction}

Turner girls, women and their family members always have several social problems. The family usually feel shock at the time of diagnosis. Turner girls are not well informed about Turner syndrome in our country, mainly because of the cultural background. The parents and the attendant doctors are afraid that Turner girls may become very anxious if they get full information about Turner syndrome. People have distorted ideas about chromosomal abnormalities in our country, and parents are psychologically isolated.

Correspondence: Dr. Keinosuke Fujita, Department of Pediatrics, Osaka City General Hospital, 2-13-22 Miyakojima-Hondori, Miyakojima-ku, Osaka 534, Japan
In 1991, we organized a Turner society in Osaka. We discussed school life, growth hormone and estrogen therapy, marriage, fertility, in vitro fertilization, osteoporosis, how to give information about Turner syndrome to Turner girls, and so on. The family are encouraged by attending the meetings. There are now several other Turner societies in different parts of Japan.

We sent a questionnaire to the members of the Turner Societies and summarized the results in this study.

\section{Materials and Method}

We sent a questionnaire to the members of the Turner Societies in order to find out their social problems they had met with during daily activities. Ninety-four responded. The response rate was $56 \%$. 


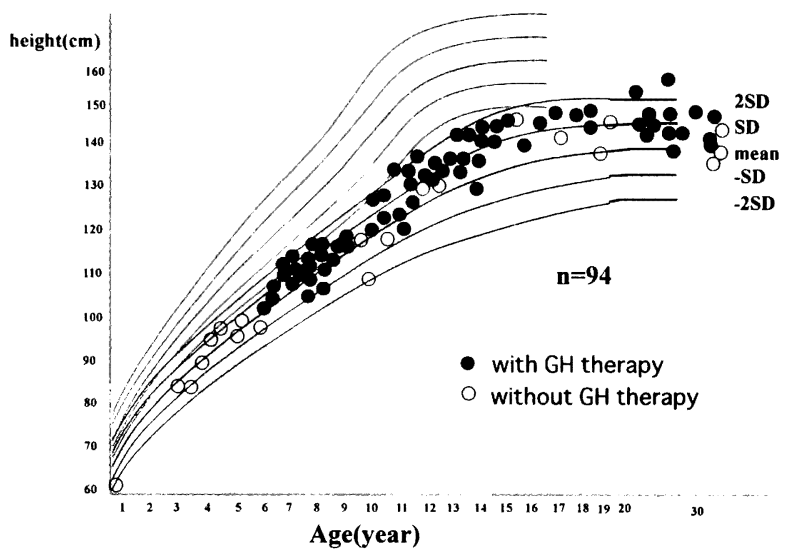

Fig. 1. The age and height distribution of each individual in this study. Closed circles indicate the individuals with GH therapy, and open circles indicate the individuals without GH therapy.

\section{During infancy}

\section{Did parents feel that the infant was difficult to bring up?}

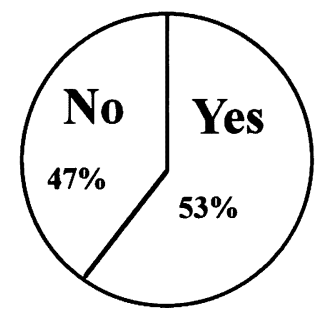

Fig. 2. Question about difficulty in bringing up Turner girs during infancy.

\section{During infancy -question to mothers-}

Did you feel that you were not good at treating the baby?

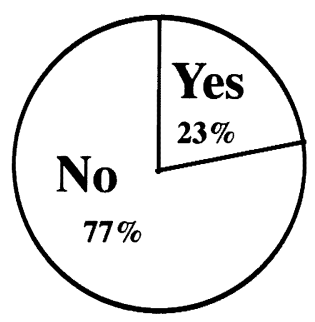

Did you feel that you were too nervous to bring up the baby?

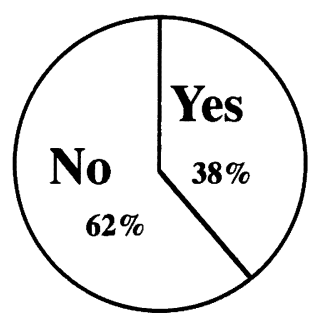

Fig. 3. Question to mothers concerning infancy.

\section{Results}

1) The age distribution was from 9 months to 33 years of age. Eleven of them were under 6 years of age. Twenty-one were between 7 and 9 , twenty-one between 10 and 12 , sixteen between 13 and 15 , seven between 16 and 18, and eigh- teen were above 19. The height distribution, and persons with and without growth hormone therapy are shown in Fig. 1.

2) During infancy.

Did parents feel that the infant was difficult to bring up? 53\% of parents answered "Yes" (Fig. 2). Did the mother feel that she was not 


\section{During school life} Was she bullied?

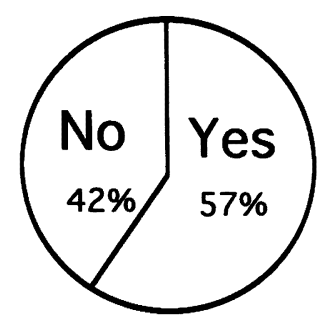

Fig. 4. Question about bullying during school life.

\section{What kinds of bullying ? How to solve the problems}

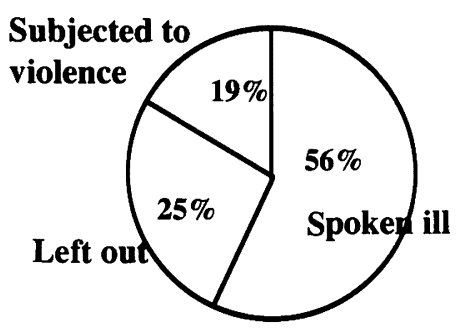

How was academic performance? (self rated)

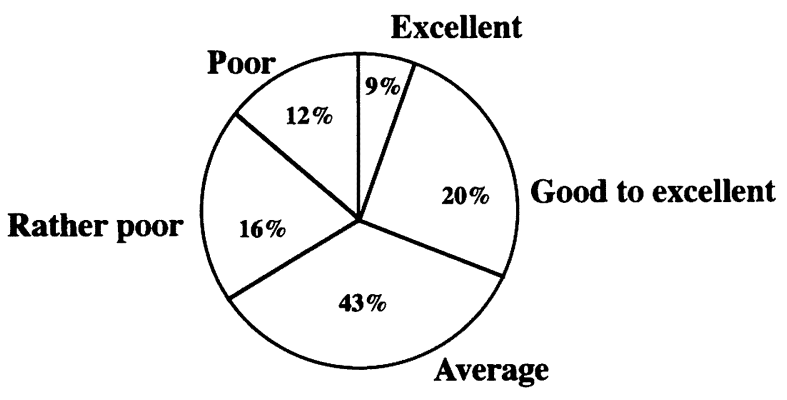

Fig. 6. Question about academic performance.

good at treating the baby? $23 \%$ of mothers answered "Yes" (Fig. 3). Did the mother feel that she was too nervous to bring up the baby? $38 \%$ of mothers answered "Yes" (Fig. 3).

\section{3) During school life.}

Was the Turner girl bullied? $57 \%$ of individuals answered "Yes" (Fig. 4). What kinds of bullying? 56\% said they were "spoken ill of". $25 \%$ said they were "left out", and $19 \%$ said they were "subjected to violence"(Fig. 5). How did they try to solve the problems? $51 \%$ of them discussed with teachers and classmates, $27 \%$ of them just ignored the problems and $22 \%$ of them endured the problems (Fig. 5).

How did they rate their own academic performance? 9\% said "Excellent", 20\% said "Good to excellent", 40\% said "Average", 16\% said "Rather poor", and 12\% said "Poor" (Fig. 6). What are your favorite subjects? $34 \%$ said Japanese language, $18 \%$ music, $13 \%$ history and geography, $12 \%$ mathematics, and $12 \%$ English. What subjects do you dislike? $39 \%$ said mathematics, $28 \%$ gymnastics, and $12 \%$ biology and chemistry (Fig. 7).

4) Do Turner girls or women get information about Turner syndrome?

Among the persons who answered the questionnaire, 62 were above 10 years of age. $43 \%$ said "Yes". When did you receive information about Turner syndrome? Fifteen of them said between 10 and 12 years of age, five between 13 and 15, none between 16 and 18, and five above 19: two were 19 years of age, two were 20 , and one was 24 (Fig. 8). Who gave you information about Turner syndrome? 54\% said parents, $24 \%$ a doctor, and $11 \%$ said that they heard about Turner syndrome by accident. How did she look when she got the information? 59\% said unchanged, $33 \%$ said that she looked all right, and 


\section{Favorite subjects}

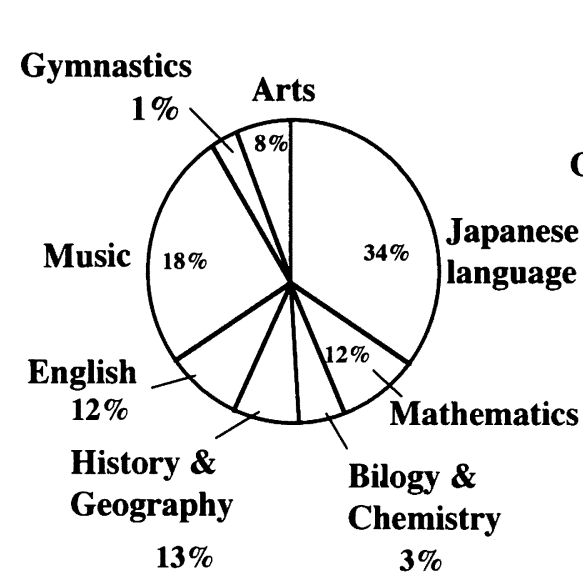

\section{Disliked subjects}

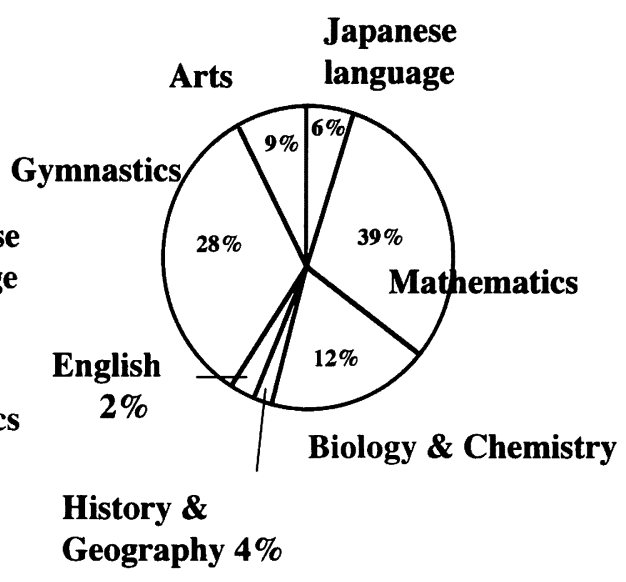

Fig. 7. Question about favorite and disliked subjects.

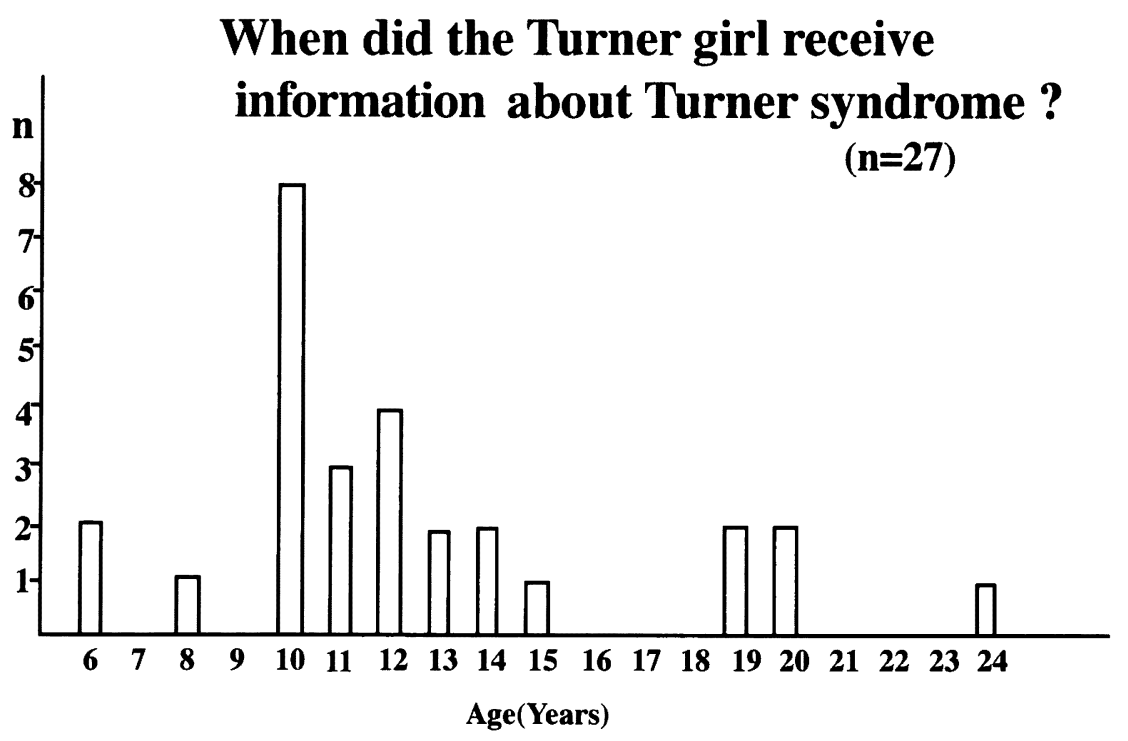

Fig. 8. Question about the time when the Turner girl received information about Turner syndrome.

$8 \%$ said that she was upset.

5) During adolescence.

Which is more important, stature or puberty? $58 \%$ said stature, $8 \%$ puberty, and $26 \%$ were undecided. Of the persons who answered the questionnaire, 19 were receiving estrogen thera- py. They were asked when they started the estrogen therapy. One started at 12 years of age, four between 13 and 15, nine between 16 and 18, and five above 19: two at 19 years of age, three at 20 , and one at 22 . The mean at the start of estrogen therapy was 17 . 
6) Adult life.

Of those who answered the questionnaire, eighteen were above 19 years of age, and ten had a job. Several questions about employment were asked. Was it easy to get a job? Seven said "Yes", and three said "No". Did you get the job that you wanted? Seven said "Yes", and three said "No". What job did you get? Six of them got office work, and one each got employment as a nurse, medical technician, helper for disabled people and in a service industry. Does short stature affect your job? Two said "Yes", six said "No", and two did not answer.

Several questions about boy friends and marriage were asked to 18 persons above 19 years of age. Do you have a boy friend? Six said "Yes", and 12 said "No". Do you have a lover? None said "Yes". Are you married? One Turner woman said "Yes". Did you or are you going to tell your partner about Turner syndrome? Eleven said "Yes", none said "No", and seven did not answer. Do you want children? Four said "No", five said that they would endure having children, two wanted in vitro fertilization, and seven did not answer. None said that they wanted to adopt a child.

\section{Discussion}

We recognized that many Turner girls, women and their families had several social problems at all stages of life. Half of the parents felt that during infancy the Turner girl was difficult to bring up. One fourth of the mothers felt that they were not good at treating the baby, and one third of the mothers suggested that they were too nervous to bring up the baby. If the diagnosis of Turner syndrome was made in infancy, the mother would understand why the baby was difficult to bring up. The mother had no need to be nervous. Early diagnosis is important.

During school life, half of the Turner girls were bullied. One fourth of them just ignored the problem, and one fourth endured it. At meet- ing of the Turner Society, parents and Turner girls themselves discussed how to solve the problems. And members recognized that these problems were not confined to them. The Turner society could help them to solve these problems.

As for academic performance, two thirds of Turner girls were average or above average. Okada reported that the percentage of Turner women entering college or university was higher than the average (1), but numerous studies have shown that some individuals with Turner syndrome have selective impairment in nonverbal visuo-spatial processing (2). As previously mentioned, $39 \%$ of them said that mathematics was not a favorite subject. If the parents know of this tendency, they can help the Turner girl to learn mathematics before it is too late.

How to give information about Turner syndrome to Turner girls is a major problem in our country (3). Parents and doctors are afraid that Turner girls may become very anxious if they get full information about Turner syndrome. Half of the Turner girls received information about Turner syndrome in our study. When they got the information, only $8 \%$ of them were upset. A knowledge of Turner syndrome is important for Turner girls, and it is not necessary to be afraid that they may become very anxious if they get full information about Turner syndrome.

Estrogen therapy was initiated at various age between 12 and 22, and the mean age was 17 years in this study. Igarashi et al. recommended that estrogen therapy should not be initiated before 12 years of age, but ideally, should be begun by 15 years of age (4). If the growth hormone therapy were initiated earlier, the height gain would be better, so that estrogen therapy could be initiated earlier. Early diagnosis is therefore important.

During adult life, employment and marriage are important. Ten of the Turner women covered by our study had a job. Seven of them answered that it was easy to get a job and the 
other 3 answered that was difficult. Most of them worked in an office. Of 18 Turner women above 19 years of age, six said that they had boy friends. This rate might be lower than average for young women. Only one Turner woman in this study was married, but most in the study are still in their early twenties; so we need to follow them up.

Nielsen suggested four additional things that can be done for Turner girls and women and their parents (5): 1 . We ought to diagnose Turner girls much earlier than at present. 2. We should give more and better information to Turner women, Turner girls and their parents. 3 . We should encourage and support Turner contact groups and take the initiative in starting more such groups in all countries. 4. More research should be conducted on Turner's syndrome, especially in relation to the improvement of treatment and life conditions in general.

The Turner societies are still in their early stage in Japan. But these societies have developed, and Turner girls, women and their families are encouraged by attending meetings.

\section{References}

1. Okada Y. The quality of life of Turner women in comparison with grown-up GH-deficient women. Endocr J 1994; 41: 345-54.

2. Rovet J. The psychoeducational characteristics of children with Turner syndrome. J Learning Disabil 1993; 26: 333-41.

3. Fujita $\mathrm{K}$, Nakajima R, Murakami H, Inada H, Kondo $\mathrm{T}$, Itagane $\mathrm{Y}$, et al. When is it appropriate to give information about Turner syndrome to Turner girls? Clin Pediatr Endocrinol 1996; 5 (suppl 7): 76-7.

4. Igarashi Y, Ogawa E, Fujieda K, Tanaka T. Treatment of Turner syndrome with transdermal $17-\beta$-estradiol. In: Hibi I, Takano K, editors. Basic and clinical approach to Turner syndrome, Amsterdam: Elsevier Science Publishers BV, 1993: 197-202.

5. Nielsen J. What more can be done for girls and women with Turner's syndrome and their parents? Acta Pediatrica Scandinavica 1989; 356 (suppl): 93-100. 